REVISTA DE LITERATURA E CULTURA RUSSA

\title{
Dostoiévski e Literatura-Mundial: apontamentos para uma solução do enigma de Mister Astley
}

Dostoevsky and World-Literature: notes for a solution to the Mister Astley's enigma

Autor: João Marcos Cilli de Araujo Universidade Estadual de Campinas, Campinas, São Paulo, Brasil Edição: RUS Vol. 12. No 20

Publicação: Dezembro de 2021 DOI: https://doi.org/10.11606/issn.2317-4765.rus.2021.189154 


\title{
Dostoiévski e Literatura-Mundial: apontamentos para uma solução do enigma de Mister Astley
}

\author{
João Marcos Cilli de Araujo*
}

Resumo: Schwarz (2000, p. 27) lembra a recorrência de personagens germanófilos e francófilos nos romances russos, figuras um tanto ridículas que, embora sejam falsários e picaretas, são os grandes defensores da modernização que acompanha o capital. Em Um jogador, romance de Dostoiévski publicado em 1867, a situação vai além. Como sua ação transcorre toda no exterior, não há sequer a necessidade de um russo francófilo ou germanófilo: os ocidentais falam por si. Contudo, diferentemente do que ocorre com os demais personagens associados ao Ocidente, há, no romance em questão, um retrato aparentemente positivo de Mister Astley, britânico que, no entender de boa parte da crítica, seria uma espécie de paradigma moral do romance. 0 que se pretende neste artigo é justamente uma problematização da leitura positiva que se faz de Mister Astley, buscando-se, ao inserir o personagem na economia-mundo capitalista e ler a obra dostoievskiana a partir da problemática da Literatura-Mundial, apontálo como o retrato do nefasto imperialismo britânico.

\begin{abstract}
Schwarz (2000, p. 27) recalls the recurrence of Germanophile and Francophile characters in Russian novels, somewhat ridiculous figures who, although they are forgers and hacks, are the great defenders of the modernization that accompanies capital. In The Gambler, a novel by Dostoevsky published in 1867 , the situation goes further. As its action takes place abroad, there is not even a need for a Francophile or Germanophile Russian: Westerners speak for themselves. However, unlike what happens with other characters associated with the West, there is, in the novel in question, an apparently positive portrait of Mister Astley, a British who, in the opinion of many critics, would be a kind of moral paradigm of the novel. What is intended in this article is a problematization of the positive reading of Mister Astley, seeking, by inserting the character in the capitalist world-economy and reading the Dostoevskian work from the problematic of World-Literature, to point him out as the portrayal of the nefarious British imperialism.
\end{abstract}

Palavras-chave: Dostoiévski; Literatura-Mundial; Imperialismo Keywords: Dostoevsky; World-Literature; Imperialism 
* Doutorando pelo Programa de Pós-Graduação em Teoria e História Literária da Universidade Estadual de Campinas (UNICAMP), Mestre em Letras pela Universidade Federal de Ouro Preto (UFOP) com dissertação a respeito de Dostoiévski, e Bacharel em Direito pela Universidade de São Paulo (USP). Atua como Professor de Educação Básica no Estado de Minas Gerais; http://lattes.cnpq. br/9960958007032400; https:// orcid.org/0000-0002-6900-7257; jmcillidearaujo@gmail.com

\section{Introdução}

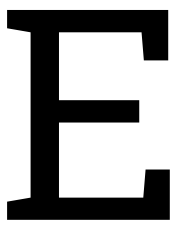

m artigo publicado no ano de 2013, Rafael de Bivar Marquese, historiador da Universidade de São Paulo, defendia que o abandono do conceito de capitalismo pela historiografia predominante no estudo acerca da escravidão brasileira oitocentista - historiografia essa marcada pelo sentido arcaico do escravismo no Brasil ou pelo enfoque na questão da agência escrava $^{1}$ - fez com que os processos históricos de longa duração e os quadros globais do capitalismo históricos, nos quais o sistema escravista brasileiro se inscrevia, fossem deixados de lado. Assim, perdia-se "a riqueza do acúmulo intelectual produzido anteriormente, na qual a discussão da relação entre escravidão e desenvolvimento capitalista dependente, periférico e excludente no país representava aspecto central". ${ }^{2}$

Ao fim do estudo, o autor busca apontar em linhas muito gerais como seria possível voltar a incorporar a dimensão mundial do capital nas análises sobre a escravidão brasileira. Propõe, assim, uma leitura atenta dos trabalhos de Fernand Braudel, Immanuel Wallerstein e Giovanni Arrighi, "que chamam atenção para a flexibilidade e alternância como elementos estruturais do capitalismo histórico". ${ }^{3}$ Para tal conjunto de autores, o elemento definidor do capitalismo não estaria no trabalho assalariado empregado na grande indústria mecanizada, mas, sim, no "capital líquido e móvel, que se desloca de uma aplicação para outra conforme as oportunidades de ganho, em uma busca incessante da acumulação pela acumulação". ${ }^{4}$

\footnotetext{
1 A grande referência no primeiro desses ramos historiográficos é 0 arcaísmo como projeto, trabalho de Fragoso e Florentino, enquanto, dentre os trabalhos produzidos com enfoque na questão da agência escrava, Visões da liberdade, de Chalhoub, permanece central. Marquese faz a ressalva de que seu artigo poderia ser acusado de cobrar algo que não esteve no horizonte dos objetivos de tais historiadores, já que nenhum deles pretendeu examinar as relações da instituição com as forças capitalistas globais. Porém, foram justamente as implicações desta exclusão que impulsionaram o autor da Universidade de São Paulo a compor a peça em questão (MARQUESE, 2013, p. 251).

2 SALLES, 2020, p. 36.

3 MARQUESE, 2013, p. 246.
}

4 Ibidem, p. 247. 
Posteriormente, em trabalho publicado no ano de 2019, o autor realiza um levantamento de abordagens sobre a escravidão atlântica com vistas a avaliar a pertinência da história global para o tratamento de determinadas temáticas, apresentando, num segundo momento, algumas considerações teóricas e metodológicas para fundamentar a construção de uma agenda de pesquisa para a história global "que tenha como cerne de suas preocupações a multiplicidade temporal da escravidão atlântica em suas relações com a dinâmica do capitalismo histórico". ${ }^{5} \mathrm{O}$ historiador menciona, por exemplo, as obras de C.L.R. James e Eric Williams, autores que teriam jogado luz sobre o papel decisivo que a escravidão negra nas Américas desempenhou na gênese do mundo moderno. Deste modo, teriam aberto caminho não apenas para entender o problema do desenvolvimento desigual na esfera do capitalismo global, mas, também, para a compreensão de como processos históricos desenrolados em diferentes partes do espaço atlântico constituíram uma unidade orgânica, "com eventos do Velho Mundo (Europa e Ásia) e do Novo Mundo (Américas) condicionando-se em um jogo de determinações recíprocas". ${ }^{6}$ Assim como no trabalho de 2013, Marquese invoca a perspectiva de Wallerstein, qualificando-a como "bastante sugestiva para a escrita da história global do trabalho escravo", já que permitiria "pensar mais diretamente a combinação variável de formas de exploração da mão de obra (assalariamento, servidão por contrato, meação, colonato, escravidão e assim por diante) como um traço essencial do capitalismo". ${ }^{7}$

São leituras que permitem romper com velhas concepções que entendem a escravidão como uma esquisitice ou exoticidade das periferias do mundo capitalista. Na verdade, ela foi parte fundamental da constituição do capitalismo e do mundo moderno como um todo. Tal tipo de leitura - ainda mais quando se vai além do trabalho escravo, apreendendo também as formas de exploração do trabalho não menos abjetas que sur-

5 Idem, 2019, p. 15.

6 Ibidem, p. 19.

7 Ibidem, p. 27. 
giram nos grandes impérios ultra marítimos com o fim formal da escravidão, bem como as formas de trabalho compulsório que com ela coexistiram ${ }^{8}$ - serve não apenas à produção de uma historiografia de olhar mais abrangente e crítico, mas, também, ao labor do crítico literário. Não por acaso, muitos dos estudos acerca de literatura que intentam ir além das fronteiras e sistemas literários nacionais recorrem a alguns dos autores investigados por Marquese. Pense-se, por exemplo, em A república mundial das letras, obra na qual a francesa Pascale Casanova opõe-se, teórica e metodologicamente, à nacionalização da literatura, apoiando-se, principalmente, em Pierre Bourdieu (com sua concepção de "campo literário) e na economia-mundo de Fernand Braudel..$^{9}$ Este último não deixa de ser importante à Cultura e imperialismo, de Edward Said, ${ }^{10}$ e, ao lado de Wallerstein, às concepções de Franco Moretti a respeito da World Literature."1

O presente artigo propõe investigar algumas das implicações que este tipo de leitura poderia trazer sobre a obra de Dostoiévski, autor cujo bicentenário celebra-se no ano de 2021. Aqui se refere mais especificamente à obra Um jogador, publicada pela primeira vez em 1867, e na qual, nos dizeres de um crítico, tem-se o único estrangeiro pintado de maneira positiva em todo o corpus do romancista russo, o inglês Mister Astley. ${ }^{12}$ Não por acaso, o crítico em questão batizou seu artigo de The enigma of Mr. Astley, ${ }_{1}^{13}$ tão inusitada é a caracterização do personagem em relação aos demais não-russos retratados por Dostoiévski.

8 Para exemplos de trabalho compulsório no Brasil oitocentista, consultar o trabalho de Gonçalves e Meyer (2011). Segundo as autoras, indígenas, recrutas, galés, africanos livres, agregados e forros compunham, no âmbito do Império brasileiro, o corpo do trabalho compulsório, corpo esse que, embora bastante diversificado, tinha como denominador comum a precariedade e a instabilidade da liberdade vivenciada.

9 Cf. CASANOVA, 2002.

10 Cf. SAID, 2011.

11 Cf. MORETTI, 2000 e 2003.

12 "He is the only positive foreigner of any standing in the whole of Dostoevsky's oeuvre", afirma Jones (2002, p. 41).

13 JONES, 2002. 
Expandir os horizontes do romance para além do contexto estritamente russo e europeu, inserindo-o nas dinâmicas históricas do capitalismo global - trata-se de uma das poucas obras do autor cuja ação não se passa na Rússia, mas, sim, na fictícia cidade germânica de Roletemburgo, tendo em seu rol de personagens sujeitos das mais diversas nacionalidades europeias -, talvez seja uma forma de se desfazer tal juízo a respeito do personagem britânico. Para tanto, talvez seja interessante pensar em termos do amplo panorama da Literatura-Mundial. Esta, na definição do Warwick Research Collective, é entendida como a literatura do sistema-mundo capitalista. Na esteira de Braudel e Wallerstein, sistema-mundo é o termo utilizado para indicar um universo social interligado, cujo funcionamento é mais ou menos autônomo, mais ou menos integrado. Geralmente, um sistema-mundo não é algo de dispersão global (e, portanto, não abarca todo o "mundo") - a exceção relevante parece ser aquela do sistema-mundo capitalista, que tem um dos indicadores de seu caráter inédito na história humana justamente no fato de ser um sistema-mundo - na concepção wallersteiniana - e, simultaneamente, um sistema mundial - no sentido de algo de extensão mundial. ${ }^{14}$ Daí, neste artigo, não se limitar a leitura de Dostoiévski ao contexto estritamente russo ou europeu; o que se busca, na verdade, é apresentar os personagens - mais especificamente o inglês Mister Astley - em sua posição na economia-mundo. Para tanto, vale lembrar que Trótski celebrizou a ideia de que, na imposição do capitalismo àquelas culturas e sociedades que lhe eram estranhas (parte, portanto, do fenômeno imperialista), as forças produtivas e as relações de produção propriamente capitalistas tendem a não suplantar, mas a coexistir com as forças e relações ali pré-existentes, no que o revolucionário russo chamou de teoria do desenvolvimento desigual e combinado. Tal teoria foi concebida "para descrever uma situação em que as formas e relações capitalistas coexistem ao lado de 'formas arcaicas de vida econômica' e relações sociais e de classe pré-existentes" ${ }^{15}$ É possível, pois, entender a modernidade como

14 WReC, 2015, p. 8.

15 Ibidem, p. 11. Tradução livre do autor do artigo. Assim se encontra o original, em inglês: 
algo, simultaneamente, singular e global, sendo que singular, aqui, não oblitera heterogeneidades internas. Partindo-se das ideias de Trótski e da concepção de sistema-mundo, para as quais o capitalismo é uno e desigual - com um centro, uma periferia e uma semiperiferia conectados numa relação de crescente desigualdade -, é possível chegar a uma literatura (ou, melhor, um sistema literário) ao mesmo tempo única e profundamente desigual. ${ }^{16}$ Portanto, afasta-se de certas concepções pós-coloniais que buscam salientar "modernidades alternativas": a escravidão nas américas, por exemplo, não representou um forma alternativa de modernidade, mas, sim, estava inserida num sistema-mundo mais amplo (o capitalismo), no qual desempenhava papel fundamental. Nas palavras do WReC, ${ }^{17}$ fazendo referência a Harootunian:

Nestes termos, os modos específicos de aparecimento da modernidade em diferentes tempos e lugares, ou suas representações nas obras da literatura - São Petersburgo na década de 1870, Dublin em 1904, Mississippi rural na década de 1930, uma vila em uma curva do Nilo no Sudão na década de 1960, Bombaim em 1975, Glasgow na década de 1990 - devem ser pensados não como "alternativos", mas como "modernidades contemporâneas ou, melhor ainda, periféricas (desde que periférico seja entendido apenas como uma relação com os centros do capitalismo [...]), em que todas as sociedades compartilham uma referência comum fornecida pelo capital global e suas necessidades" ${ }^{18}$

Tem-se, pois, um tríptico, o sistema-mundo capitalista/modernidade/Literatura-Mundial, em que o capitalismo é o subs-

\footnotetext{
"[t]he theory of 'combined and uneven development' was therefore devised to describe a situation in which capitalist forms and relations exist alongside 'archaic forms of economic life' and pre-existing social and class relations".

16 MORETTI, 2000, n.p.

17 WReC, 2015, p. 14.

18 Traduziu-se, mais uma vez. Eis o original: "In these terms, the specific modes of appearance of modernity in different times and places, or the representations of them in works of literature - St Petersburg in the 1870s, say, Dublin in 1904, rural Mississippi in the 1930s, a village on a bend in the Nile in the Sudan in the 1960s, Bombay in 1975, Glasgow in the 1990s - ought to be thought about not as 'alternative' but as 'coeval or, better yet, peripheral modernities (as long as peripheral is understood only as a relationship to the centers of capitalism[...]), in which all societies shared a common reference provided by global capital and its requirements"'.
} 
trato, o horizonte político da Literatura-Mundial, enquanto a modernidade é seu conteúdo e sua forma: "modernidade é tanto o que a literatura mundial indexa ou é 'sobre' e o que dá à literatura mundial suas características formais distintivas" ${ }^{19}$

\section{Adoradores de Baal: uma crítica dostoievskiana à Inglaterra e seu imperialismo}

Diferentemente de todos os demais estrangeiros representados em Um jogador, Astley é descrito com bons olhos por Aleksiéi Ivânovitch, o preceptor que serve de narrador ao romance, sujeito sempre esnobado pela aristocracia russa e os pomposos franceses que compõem a comitiva de seu empregador, um general decadente. O narrador considera-se amigo do britânico, sentimento que julga ser recíproco. Inclusive, quando o narrador se envolve em uma confusão com certo barão prussiano e passa a falar em duelo, Astley é o primeiro padrinho que lhe vem à cabeça: "Ele gosta de mim e, certamente, não se recusará" ${ }^{20}$ Como já referido, não é só o narrador que destaca os aspectos positivos do inglês: a crítica também o faz. Frank ${ }^{21}$ lembra (e concorda) que Savage, ao salientar que Aleksiéi é um narrador não confiável, de modo que seu quadro de "Polina [a enteada do general, jovem por quem o protagonista nutre intensos e ambíguos sentimentos] é distorcido mesquinhamente por suas próprias frustrações e ressentimentos", afirma que as duas personagens que funcionam como padrão moral à narrativa - $\mathrm{a}$ avó [do general, matriarca russa cuja morte $o$ empregador de Aleksiéi espera ansiosamente, visando sua herança] e, justamente, Mister Astley -, "falam de Polina em termos muito elevados". O mesmo Frank afirma que Astley, considerado por ele como modelo das verdadeiras virtudes do

19 Ibidem, p. 15: "modernity is both what world-literature indexes or is 'about' and what gives world-literature its distinguishing formal characteristics".

20 DOSTOIÉVSKI, 2011 b, p. 72.

21 FRANK, 2013, p. 236. 
cavalheirismo, teria como ponto negativo apenas a limitação de seu mundo inglês tomado por um "prosaico senso prático", o que seria representado por sua atividade empresarial..$^{22}$ Os elogios de Frank a Mister Astley não param por aí. Ele acredita que Aleksiéi, não obstante toda a sua fraqueza, gera simpatia em razão de sua honestidade para consigo mesmo e seu olhar certeiro a desrespeitar hipocrisias, pretensões e falsidades da Europa Ocidental. Essa "cativante impetuosidade e sinceridade" acabaria por conquistar todas as personagens "positivas" do romance, Polina, a avó e... Mister Astley. ${ }^{23}$ A situação é no mínimo curiosa, uma vez que todos os demais não-russos são descritos de maneira muito negativa e, numa análise de outros escritos dostoievskianos, fica claro que o romancista também olhava para a Terra da Rainha com olhos profundamente críticos.

Notas de inverno sobre impressões de verão - o travelogue composto por Dostoiévski acerca de suas andanças pela Europa Ocidental, realizadas no ano de 1862 - talvez seja a obra na qual isso aparece de maneira mais evidente. $O$ capítulo dedicado a Londres é, inclusive, intitulado Baal, a divindade semítica erigida ao demônio pelo cristianismo. Dostoiévski nota a poluição que assola a cidade, com seu "envenenado Tâmisa" e o "ar impregnado de carvão de pedra", bem como a pobreza da classe trabalhadora, uma "população seminua, selvagem e faminta". ${ }^{24} \mathrm{O}$ autor não deixa de reconhecer o que há de grande e imponente na cidade, como as linhas férreas e o Palácio de Cristal, destacando toda a glória e triunfo que parece haver naquilo, que pode levar alguém a indagar: "Não será este, de fato, o 'rebanho único'? Não será preciso considerá-lo como a verdade absoluta, e calar para sempre?". ${ }^{25} \mathrm{O}$ encanto londrino, todavia, estaria a ocultar certa profecia apocalíptica:

Isso constitui não sei que cena bíblica, algo sobre a Babilônia, uma profecia do Apocalipse que se realiza aos nossos

22 Ibidem, p. 237.

23 Ibidem, p. 237.

24 DOSTOIÉVSKI, 2011a, p. 115.

25 Ibidem, p. 116. 
olhos. Sente-se a necessidade de muita resistência espiritual e muita negação para não ceder, não se submeter à impressão, não se inclinar ante o fato e não deificar Baal, isto é, não aceitar o existente como sendo o ideal... ${ }^{26}$

A dimensão colossal da cidade imobilizaria a alma faminta dos trabalhadores, sempre a buscar conforto no gim e na devassidão, vez "que tudo deve ser assim mesmo". ${ }^{27}$ Assim, os proletários chegam a ser descritos de maneira animalesca:

Contam-me, por exemplo, que nas noites de sábado meio milhão de operários de ambos os sexos, acompanhados de suas crianças, espalham-se como um mar por toda a cidade, agrupando-se mais densamente em determinados bairros, e durante a noite inteira, até às cinco da manhã, festejam o sabá, isto é, empanturram-se de comidas e bebidas como uns animais, por toda a semana. Todos eles sacrificam para tal fim as economias semanais, fruto de um trabalho estafante e acompanhado de maldição. ${ }^{28}$

O autor também trata de zombar do anglicanismo, religião que ele vê como elitista, a clara concretização da igreja como empresa. Os pastores e bispos são descritos como altivos, ricos e luxuosos, ao mesmo tempo em que são muito pedantes. Eles jamais iriam à casa de um pobre, e este também nunca seria admitido na igreja, vez que não teria como arcar com as despesas de seu lugar no banco. Assim, os casamentos operários seriam quase sempre ilegais, levando a uniões em que não raro os maridos bateriam terrivelmente nas mulheres, deformando-as até a morte, "o mais das vezes com tenazes, dessas que se usam para revolver carvão na lareira" ${ }^{29}$ Trata-se, na visão do autor, da religião dos ricos, já sem qualquer máscara, embuste e enganação.

Importante notar que Dostoiévski também desenvolve uma crítica ao anglicanismo enquanto ferramenta ideológica do imperialismo britânico. Os religiosos, ele diz, possuem nas missões sua diversão:

26 Ibidem, p. 116.

27 Ibidem, p. 116-117.

28 Ibidem, p. 117.

29 Ibidem, p. 122. 
Percorrem todo o globo terrestre, penetram nas profundezas da África, a fim de converter um selvagem, e esquecem de milhões de selvagens em Londres, porque estes não têm como lhes pagar. Mas os ingleses ricos e, de modo geral, todos os bezerros de ouro desse país são religiosos ao extremo, de maneira sombria, taciturna, peculiar. ${ }^{30}$

Por fim, Dostoiévski termina seu capítulo com, poder-se-ia dizer, pontos positivos para Londres, ou, como o autor se refere, "a cidade satânica". Isso porque, na concepção do autor, Baal não esconde de si seus aspectos selvagens, diferentemente de Paris, outra das cidades visitadas ao longo da narrativa. Não "o perturbam sequer a miséria, o sofrimento, os murmúrios e o embotamento da massa". ${ }^{31}$ No caminho oposto ao da França, todos os aspectos terríveis da cidade ali se revelam, em plena luz do dia, sem qualquer tipo de maquiagem ou ocultamento. Se ambos os universos são terríveis, decadentes e moralmente abomináveis, ao menos Londres, com seus trabalhadores bestializados, seus religiosos empreendedores e sua atmosfera poluída, não o nega:

Ao contrário do parisiense, ele não se esforça, assustado, em se convencer, animar, em comunicar a si mesmo que tudo está tranquilo e bem-sucedido. Ele não esconde, como em Paris, os pobres em alguma parte, para que não lhe perturbem o sono e não o assustem inutilmente. A exemplo do avestruz, o parisiense gosta de esconder a cabeça na areia, a fim de não ver os caçadores que o estão alcançando. Em Paris... Mas, que é isto? Mais uma vez, não estou em Paris... Quando será, meu Deus, que me acostumarei à ordem?... ${ }^{32}$

Eis, portanto, a visão nada lisonjeira que Dostoiévski concebera a respeito de Londres, poucos anos antes de criar Mister Astley para seu romance. O que o discurso de Aleksiéi, a louvá-lo, possui de oculto? As evidências espalhadas pela narrativa de Um jogador levam a crer que, não obstante as palavras do preceptor - narrador que não é confiável -, por meio do personagem britânico talvez se promova uma das críticas mais interessantes do romance.

30 Ibidem, p. 122.

31 Ibidem, p. 123.

32 Ibidem, p. 123. 
Em primeiro lugar, destaca-se o fato de, ao longo da narrativa, o inglês demonstrar certa onisciência, tomando conhecimento de fatos que, a princípio, não poderia ter acesso. No início do Capítulo VIII, por exemplo, Aleksiéi acaba de ser demitido e, ao encontrar Mister Astley a caminhar na rua, surpreende-se ao saber que seu companheiro já estava inteirado de tudo. No diálogo que travam, o britânico esquiva-se, negando maiores informações a respeito de como ficara sabendo dos fatos e, ao mesmo tempo, reiterando sua amizade pelo preceptor: "Eu sei", limita-se ele a dizer, "isto é, tive a oportunidade de ficar sabendo. Para onde partirá agora? Gosto do senhor e, por isso, vim procurá-lo". O narrador contenta-se com a esquiva de seu companheiro e apenas ao leitor deixa escapar, de maneira bem ligeira, a surpresa pelo conhecimento de seu interlocutor: "O senhor é uma pessoa simpática, mister Astley disse eu (aliás, ficara extremamente surpreso: como sabia ele de tudo?)" ${ }^{33} \mathrm{Na}$ mesma conversa, mas um pouco mais adiante, Aleksiéi faz insinuações a respeito das relações entre Polina e Des Grieux, farsante francês que acompanha o general visando abocanhar a herança da avó (ele emprestara dinheiro ao nobre russo, de modo que a expectativa pela morte da matriarca lhe serve como uma espécie de garantia). Novamente, 0 inglês, que até então agira sempre de maneira muito discreta, o surpreende. "Não pode dizer nada de concreto sobre aquele marquês [Des Grieux, que por vezes é apresentado também com o título de conde] e Miss Polina, além de meras suposições?", o inglês indaga. "Mais uma vez fiquei surpreso com uma pergunta assim categórica, partindo de um homem tão encabulado como Mister Astley" é o comentário do narrador, que, em seguida, ouve uma grande admoestação do britânico pelos dizeres sem fundamento que realizara a respeito da enteada do general..$^{34}$ Por fim, o próprio Aleksiéi se irrita e dispara contra o interlocutor:

- Sabe de uma coisa? - exclamei de repente, fixando os olhos em Mister Astley. - Tenho a impressão de que o senhor já ouviu falar de tudo isso, e - sabe de quem? - da pró-

33 DOSTOIÉVSKI, 2011b, p. 77.

34 Ibidem, p. 78. 
pria Miss Polina!

Mister Astley olhou-me surpreendido.

- O senhor está com os olhos brilhando, e eu leio neles uma suspeita - disse, retomando no mesmo instante a tranquilidade anterior. - No entanto, não tem qualquer direito de expor as suas suspeitas. Não lhe posso reconhecer tal direito e recuso-me inteiramente a responder à sua pergunta. ${ }^{35}$

O diálogo parece evidenciar que o calado e, aparentemente, despreocupado Mister Astley talvez seja muito menos confiável do que ele próprio busca mostrar-se. O narrador acredita que o inglês se aproxima dele de maneira desinteressada, mas passagens como a exposta demonstram que a suposta amizade entre os dois talvez seja uma forma que o britânico encontrou de penetrar de maneira mais acentuada na comitiva do general, angariando, assim, informações capazes de lhe colocar em melhores posições no que diz respeito às suas pretensões (assim como Des Grieux, o gentleman também possui interesses em Polina). Sua recusa em revelar ao preceptor como tomara conhecimento de tudo parece muito mais uma tentativa de esquiva do que, como ele tenta levar seu interlocutor a crer, uma defesa da honra da jovem. É ele que, ao final da narrativa, informa a Aleksiéi o amor verdadeiro de Polina pelo preceptor - não é absurdo, portanto, supor que Astley visse no jovem um concorrente.

As situações do mesmo Capítulo VIII apenas aumentam tais suspeitas. O britânico conta ao preceptor que Blanche, francesa que se apresenta como parente de Des Grieux e por quem o general encontra-se apaixonado, já havia frequentado Roletemburgo alguns anos antes. À época, contudo, ostentava outro nome e se fazia ver na companhia de certo príncipe. Este, posteriormente, a abandonou, e a jovem se lançou à caça de um novo endinheirado capaz de manter sua vida de luxo e gastança exacerbada. Aleksiéi acredita que a história é um exemplo claro do caráter interesseiro e fútil da francesa, e acaba por repreender Mister Astley por este não os ter alertado antes a respeito do comportamento de Blanche. O britânico diz que de nada serviriam seus avisos, pois o general seria um 
homem completamente perdido e, no que diz respeito a Polina, o fato de terem se conhecido há pouco não lhe teria permitido qualquer tipo de alerta. Por fim, ele se esquiva de um jeito muito semelhante ao que usara no anterior questionamento de Aleksiéi.: "já lhe disse que não posso reconhecer-lhe o direito de fazer-me certas perguntas, apesar de gostar sinceramente do senhor". ${ }^{36}$

Ora, não só ele usa as informações que tem da maneira que lhe parece mais conveniente, ainda que isso possa prejudicar aqueles com quem diz se importar (Polina, por exemplo), como também fica claro que o narrador, embora o considere um amigo, também por ele é tratado com a soberba que a elite costuma utilizar em relação àqueles que considera seus inferiores. A conversa de ambos, destaca-se, é interrompida pela inesperada chegada da avó, até então considerada moribunda. O inglês demonstra especial interesse na senhora (cuja história envolvendo a herança conhecia bem), e esta não deixa de notá-lo, com ironia: "Inglês. Por isso é que ele fixou assim os olhos em mim e permanece incapaz de descerrar os dentes. Aliás, eu gosto de ingleses" ${ }^{37}$ Inclusive, ele mesmo o confessa, pouco depois, murmurando ao pé do ouvido do narrador: "Ela me interessa profundamente". ${ }^{38}$

No Capítulo XIII, Mister Astley mais uma vez tem um comportamento digno de desconfiança e que, em certa medida, poderia justificar seu interesse na avó. Após se ausentar misteriosamente de Roletemburgo (ele supostamente teria sido chamado a Frankfurt a negócios), reaparece justamente quando a avó consome uma verdadeira fortuna na roleta. $O$ momento não poderia ser mais oportuno, vez que a matriarca, desprovida de recursos para retornar à Rússia, requer-lhe "três mil francos emprestados por uma semana". O empréstimo, claro, não viria sem boas garantias, como afirma a própria avó: "Tranquiliza-o, para que não pense alguma coisa e não me recuse isso. Pai meu, ainda sou bastante rica. Possuo três aldeias

36 Ibidem, p. 84.

37 Ibidem, p. 90.

38 Ibidem, p. 90. 
e duas casas. E ainda se encontrará algum dinheiro, não trouxe tudo comigo" ${ }^{39} \mathrm{O}$ inglês aparece mesmo antes que a avó pudesse terminar a frase, não hesitando em entregar-lhe a quantia e, em contrapartida, receber uma nota promissória. Bom coração? Ou interesse nos eventuais proveitos que a promissória pudesse lhe trazer? Nesse sentido, não parece haver diferença substancial entre o britânico e a sua contraparte francesa, Des Grieux, que notoriamente emprestava dinheiro ao general.

Todas essas passagens fornecem elementos para que se construa uma imagem de Mister Astley como alguém capaz de manipular e mentir, muito longe de ser o paradigma moral do romance. Mas, talvez, o momento fundamental para a compreensão do verdadeiro papel do inglês na obra - e, consequentemente, da crítica que Dostoiévski busca promover -, encontre-se justamente no último capítulo. Quando o britânico se depara com um miserável e perdido Aleksiéi ao final da narrativa, este, em determinado momento da grande conversa que travam, lhe pergunta: "O senhor é produtor de açúcar, Mister Astley?". "Sim", o inglês responde, "faço parte da sociedade Lowell \& Comp., que explora uma famosa usina de açúcar". ${ }^{40}$

No nível da descrição, o inglês é, sempre, um impecável cavalheiro. Mas quando se atém à narração, à "relação necessária dos personagens com as coisas e com os acontecimentos - nos quais realiza o destino deles, e através dos quais eles atuam e se debatem", ${ }^{41}$ Astley se revela de maneira bem diversa. Na esteira do método narrativo defendido por Lukács, o drama dos personagens é, também, o drama das instituições no seio das quais eles se movem, o drama das coisas com as quais eles convivem, o drama do ambiente em que eles travam suas lutas e dos objetos que servem de mediação às suas relações. ${ }^{42} \mathrm{O}$ drama de Mister Astley é, nesse sentido, o drama do capitalismo predatório em escala global e do nefasto imperialismo europeu.

39 Ibidem, p. 90.

40 Ibidem, p. 213.

41 LUKÁCS, 1965, p. 46.

42 Ibidem, p. 46. 
Em brilhante análise da obra de Jane Austen, Said mostra a importância do espaço geográfico na construção de Mansfield Park (1814): o que sustenta materialmente a vida confortável que as protagonistas levam é a propriedade de Bertram, o patriarca, em Antígua - e, em última instância, os horrores da escravidão que lá impera. ${ }^{43}$ Não por acaso, Eagleton ${ }^{44}$ recorda que um dos personagens do romance afirma a impossibilidade de se ser, ao mesmo tempo, rico e honesto. E durante boa parte da obra a ação se refere a toda uma série de questões cujo denominador comum é o espaço: sir Thomas está em Antígua para melhorar as coisas lá e garantir a prosperidade da casa.

O Império Britânico pôs fim à escravidão em suas colônias na década de 30 do século XIX. Trinta anos antes, portanto, do momento em que se passa a narrativa de Dostoiévski. Contudo, e Conrad foi mestre em mostrá-lo, a abolição da escravatura não implicou, nas colônias europeias, em formas de exploração do trabalho menos desumanas ou menos atrozes. Assim, sob os pés do "justo" Mister Astley, a sustentá-lo, talvez esteja toda a dimensão, todo o horror da empreitada imperialista da Europa, representada por sua produção de açúcar. E mais: as luzes e todo o humanismo pretensamente universal, os mesmos que Dostoiévski critica nas Notas..., só foram possíveis ao se erguerem sobre o alicerce do escravismo. A prosperidade europeia e toda a filosofia que o protagonista de Um jogador também tanto critica e, ao mesmo tempo, tanto tenta emular, só puderam existir com a escravização dos africanos e a definição do que seria "o Negro".

Trata-se da tese de Mbembe, em seu Crítica da Razão Negra:

o Negro e a raça têm significado, para os imaginários das sociedades europeias, a mesma coisa. [...)] [A] sua aparição no saber e no discurso modernos sobre o homem (e, por consequência, sobre o humanismo e a Humanidade) foi, se não simultâneo, pelos menos paralelo; e, desde o início do século XVIII, constitui, no conjunto, o subsolo (inconfessado e muitas vezes negado), ou melhor, o núcleo complexo a partir do qual o projeto moderno de conhecimento - mas também de governação - se difundiu. ${ }^{45}$

43 SAID, 2011, n.p.

44 EAGLETON, 2003, p. 85.

45 MBEMBE, 2014, p. 10. 
Ou seja: o surgimento do conceito de homem universal, caro à Europa Ocidental, vem em conjunto com a separação da humanidade entre os brancos - aqueles que seriam, de fato, homens - e negros - espécie de semi ou quase humanos, cujo status inferior justificaria a empresa da escravização e do colonialismo. Para o liberalismo, herdeiro direto da filosofia das luzes, a diferenciação permanece fundamental: Mbembe mostra o paradoxo que se encontra em sua origem, vez que as ideias liberais implicam, de maneira intrínseca, em uma relação de produção e destruição com a liberdade - nesse sentido, para o camaronês, a escravatura dos Negros representaria o ponto culminante desta destruição. Nas palavras de Mbembe. ${ }^{46}$

Segundo Foucault, o paradoxo do liberalismo é que "é necessário, por um lado, produzir a liberdade, mas esse próprio gesto implica que, do outro lado, se estabeleçam limitações, controles, coerções, obrigações apoiadas em ameaças, etc.". A produção da liberdade vem portanto a um custo cujo princípio de cálculo é, acrescenta Foucault, a segurança e a proteção. Por outras palavras, a economia do poder característica do liberalismo e da democracia do mesmo tipo assenta no jogo cerrado da liberdade, da segurança e da proteção contra a omnipresença da ameaça, do risco e do perigo. Tal perigo pode ser resultado do desencaixe do jogo de interesses de diversos componentes da comunidade política. Mas pode também consistir em perigos de origem exterior. Em ambos os casos, "o liberalismo empenha-se num mecanismo que terá, a cada instante, de decidir a liberdade e a segurança dos indivíduos à volta desta noção de perigo". O escravo negro representa este perigo.

$\mathrm{Na}$ esteira de Eagleton, tem-se, aqui, a ambivalência trágica da modernidade: existem várias maneiras por meio das quais, de maneira faustiana, a virtude e sua negação encontram-se interligadas: "como Michael Hardt e Antonio Negri argumentam, 'o mal, a barbárie e a licenciosidade do Outro colonizado são o que tornam possível a bondade, a civilidade e a propriedade do Eu europeu"'. ${ }^{47}$ Isto é: a virtude depende de seu oposto

46 Ibidem, p. 143.

47 EAGLETON, Op. cit., p. 246. "As Michael Hardt and Antonio Negri argue, 'the evil, barbarity, and licentiousness of the colonized Other are what make possible the goodness, civility, and propriety of the European Self"'. 
para definir-se. A exploração imperialista, portanto, talvez seja o grande subtexto por trás dessa pequena, porém intensa obra que é Um jogador. Astley se veste de maneira muito asseada, é sempre educado com todos e não deixa de se irritar frente a insinuações que possam prejudicar uma dama - um homem virtuoso, pois, um verdadeiro gentleman. Mas a que custo? Todo o comportamento limpo, ideal, do inglês é sustentado pela barbárie inominável (são os ecos conradianos: "o horror! o horror!") da expansão imperial, pelo açúcar com o qual lucra. Frank e Savage, por escreverem de um ponto de vista privilegiado no que diz respeito à expansão capitalista, parecem não o notar. Neste trabalho, escrito, assim como a obra de Dostoiévski, do ponto de vista da periferia do capital, isso aparece de maneira mais clara e evidente. Partindo da periferia, o russo é capaz de apontar que até a experiência burguesa do trabalho não é algo tão inequívoco quanto se quer fazer crer. Como afirma Sloterdijk, o mesmo burguês que se afirma um eu sujeito de poder justamente porque trabalha quer fazer com que se esqueça que o modo pelo qual se organiza seu trabalho é, no mínimo, questionável, o que é especialmente válido para aqueles como Astley, os capitalistas e agentes financeiros. Afinal de contas, se o trabalho é realmente aquilo capaz de criar um título de direito a um eu político, o que dizer daqueles que, seja em Antígua ou na periferia londrina, trabalham para esses "trabalhadores" burgueses? ${ }^{48}$ Nas palavras do autor,

A situação do proletariado, privado de seus direitos durante uma grande parte do século XIX e em períodos do século XX [o que dizer, então, dos escravizados nas Américas ou dos servos na Rússia!!, não deixou, por isso, que a sociedade burguesa se aquietasse. Precisamente o princípio do desempenho, sucesso e privilégio para os mais hábeis, foi erodido pelo curso do desenvolvimento. "O trabalho liberta": tal sentença foi soando cada vez mais cínica a cada década, até ser colocada pela última vez sobre o portão de entrada de Auschwitz. ${ }^{49}$

$48 \mathrm{E}$ aqui se aplica muito bem o aceno que Marquese faz a Braudel, Wallerstein e Arrighi e sua lembrança de que o elemento definidor do capitalismo não estaria no trabalho assalariado empregado na grande indústria mecanizada, mas, sim, no capital líquido e móvel, que se desloca de uma aplicação para outra conforme as oportunidades de ganho, em uma busca incessante da acumulação pela acumulação.

49 SLOTERDIJK, 2012, p. 107. 
Assim como os personagens franceses, Astley também é uma variante de tipos muito recorrentes na literatura ocidental da qual Dostoiévski era leitor. Jones ${ }^{50}$ aponta possíveis analogias com Indiana, de George Sand, cujo personagem Sir Ralph Brown transmuta sua profunda paixão pela heroína em uma vida de servidão à amada, buscando protegê-la de pretendentes mais predatórios, superficiais e sem princípios. $O$ autor menciona, também, os nobres e benfeitores heróis de Charles Dickens, autor que, como Sand, figura entre as leituras favoritas de Dostoiévski. ${ }^{51}$

O próprio Jones reconhece que não se trata de uma mera transposição de um tipo literário, mas de uma complexa transmutação típica das narrativas do romancista russo: a atmosfera gótica do romance de Sand, "junto com seu apelo implícito pela emancipação das mulheres, é transmutada de acordo com um padrão familiar em uma comédia de Dostoiévski construída sobre uma psicologia de extremos". ${ }^{52} \mathrm{O}$ que o crítico parece não perceber é que tal transmutação gera, também, uma inversão no valor que Astley ocupa no romance. Ele não é o bondoso e dedicado herói, mas, sim, a encarnação do que há de mais frio, utilitário e abominável na ordem burguesa. Chega a ser curioso que Jones trace paralelos entre o personagem de Sand e Astley no que diz respeito às tentativas de proteger suas amadas "de homens mais predatórios, sem princípios e apenas superficialmente brilhantes" ${ }^{\prime 3} \mathrm{Na}$ narrativa de Dostoiévski, Astley é justamente a expressão máxima de um caráter predatório e sem princípios. Ele revela, talvez, a verdadeira face de Sir Ralph Brown, personagem que também

50 JONES, Op. cit., pp. 40-41.

51 Ibidem, p. 41. 0 autor salienta que seria tolice indicar um único personagem como modelo para Astley. Contudo, ele afirma não haver mistérios a respeito de sua proveniência literária: "His name, as G. M. Fridlender first reminded us, is taken from Elizabeth Gaskell's Ruth. While there is no character of this name in Mrs. Gaskell's novel, the non-conformist minister Mr. Benson, or Mr. Farquar in his relationship with Jemima Bradshaw, have important characteristics in common with Dostoevsky's hero" (Ibidem, p. 40).

52 Ibidem. Traduziu-se livremente a partir do original: "The Gothic atmosphere of Sand's novel, together with its implicit plea for the emancipation of women, is transmuted according to a familiar pattern into a Dostoevskian comedy built on a psychology of extremes".

53 Ibidem, p. 41:"From more predatory, unprincipled and superficially brilliant men". 
extrai sua fortuna da barbárie imperialista, fato que não passa despercebido a Jones: "Sir Ralph Brown, como Mister Astley, deve sua fortuna ao comércio nas colônias das Índias Ocidentais (embora em café em vez de açúcar)" ${ }^{54}$

Tais referências aos espaços imperiais não eram raras. $\mathrm{Na}$ verdade, Said chega a notar a sua presença em quase todas as partes da cultura inglesa e francesa do século XIX e começo do $\mathrm{XX}$, com especial destaque para o romance inglês. $\mathrm{O}$ próprio Dickens apresenta, em muitos casos, homens de negócios ligados ao império, sendo Dombey (Dombey and Son, 1848) e Quilp (The old curiosity shop, 1840) dois exemplos dignos de nota. ${ }^{55}$ Assim, ainda mais quando se leva em conta o caráter parodístico de Um jogador, muito provavelmente os laços de Astley com o Império Britânico não são uma construção casual. Contudo, o enigma do personagem inglês permaneceu sem solução, revelando que, mesmo quando se considera a expansão dos estudos pós-coloniais nas universidades, ainda há algo de verdade na afirmação de Said de que a crítica, quase sempre extremamente meticulosa e engenhosa em encontrar temas de discussão, deu pouca atenção a essas realidades coloniais e imperiais. ${ }^{56}$

\section{Breves considerações finais}

Buscou-se, ao longo deste trabalho, fornecer elementos para uma "leitura em contraponto" do personagem Mister Astley. Segundo Said, ler em contraponto significa entender o que está envolvido quando "um autor mostra, por exemplo, que uma fazenda colonial de cana-de-açúcar é considerada importante para o processo de manutenção de um determinado estilo de vida na Inglaterra" ${ }^{57}$ No caso dostoievskiano, isso

54 Ibidem, p. 41: "Sir Ralph Brown, like Mr. Astley, owes his fortune to trade in the West Indian colonies (though in coffee rather than sugar)".

55 SAID, Op. cit.

56 SAID, Op. cit.

57 Ibidem, n. p. 
muda tudo, revelando o lado algo nefasto de um personagem que, na contramão de todos os outros estrangeiros apresentados por Dostoiévski, foi lido e interpretado pela crítica como marcadamente positivo. Tendo-se em vista o passado colonial e imperial do Brasil, tais elementos não poderiam passar despercebidos. Afinal de contas, como lembra Said, "para quem tem um passado colonial, o tema imperial é determinante em sua formação, e ele irá atraí-lo, se você por acaso também for um crítico dedicado da literatura europeia". ${ }^{58}$

Se Astley é apreciado pelo narrador e descrito de uma maneira a acentuar seus modos cavalheirescos, quando se pensa o seu lugar na economia-mundo - isso é, seu lugar na divisão do trabalho e nos fluxos globais de mercadorias, capital e trabalho -, o que se tem é um sujeito que sustenta toda a sua vida confortável e elegante sobre os alicerces imperialistas e as atrocidades a eles diretamente relacionadas. Assim, a breve referência às empreitadas açucareiras do personagem talvez seja uma das passagens mais significativas do romance, servindo não só para que sob ele se lance um olhar capaz de inverter o polo moral que o britânico ocupa na narrativa, mas, também, para que se reinterpretam os modelos literários nos quais Astley foi baseado (como Sir Brown, de Sand).

Schwarz lembra a recorrência de personagens germanófilos e francófilos nos romances russos, figuras um tanto ridículas que, embora sejam falsários e picaretas, são os grandes defensores da modernização que acompanha o capital..$^{59} \mathrm{Em} U \mathrm{Um}$ jogador, a situação vai além. Como sua ação transcorre toda no exterior, não há sequer a necessidade de um russo francófilo ou germanófilo: os ocidentais, baseados em figuras muitas vezes célebres do cânone ocidental, falam por si. E nesse processo, a alquimia dostoievskiana transmuta-lhes o valor, revelando o que há de mais falso e bárbaro em seu suposto heroísmo.

58 Ibidem, n. p.

59 Schwarz, 2000, p. 27 


\section{Referências bibliográficas}

CASANOVA, Pascale. A República Mundial das Letras. Tradução de Marina Appenzeller. São Paulo: Estação Liberdade, 2002.

DOSTOIÉVSKI, Fiódor. O crocodilo e Notas de inverno sobre impressões de verão. Tradução de Boris Schnaiderman. São Paulo: Editora 34, 2011a.

DOSTOIÉVSKI, Fiódor. Um jogador. Tradução de Boris Schnaiderman. São Paulo: Editora 34, 2011b.

EAGLETON, Terry. Sweet Violence: The Idea of the Tragic. Oxford: Blackwell, 2003.

FRANK, Joseph. Dostoiévski: os anos milagrosos (1865-1871). Tradução de Geraldo Gerson de Souza. São Paulo: Edusp, 2013. GONÇALVES, Andréa Lisly; MEYER, Marileide Lázara Cassoli. Nas fímbrias da liberdade: agregados, índios, africanos livres e forros na Província de Minas Gerais (século XIX). Varia hist., Belo Horizonte, v. 27, n. 46, p. 645-663, dec. 2011. Disponível em <http://www.scielo.br/scielo.php?script=sci_arttext\&pi$\mathrm{d}=$ S0104-877520110002000

13\&lng=en\&nrm=iso>. Acesso em 06 abr. 2021. https://doi. org/10.1590/S0104-87752011000200013.

JONES, Malcolm V. The Enigma of Mr. Astley. In: Dostoevsky Studies, v. 6, 2002, pp. 39-47.

LUKÁCS, György. Ensaios sobre literatura. Vários tradutores. Rio de Janeiro: Civilização Brasileira, 1965.

MARQUESE, Rafael de Bivar. As desventuras de um conceito: capitalismo histórico e historiografia sobre a escravidão brasileira". Revista de História. São Paulo, n.169, pp. 223- 253, Julho/Dezembro 2013.

MARQUESE, Rafael de Bivar. A história global da escravidão atlântica: balanço e perspectivas. Esboços, Florianópolis, v.26, pp. 14-41, jan./abr. 2019.

MBEMBE, A. Crítica da razão negra. Tradução de Marta Lança. 1a. Edição. Lisboa: Antígona Editores Refractários, 2014. 
MORETTI, Franco. Conjectures on World Literature. New Left Review, 1 (edição digital), 2000. Disponível em <https://newleftreview.org/issues/II1/articles/franco-moretti-conjectures-on-world-literature>. Acesso em 07 de julho de 2021.

MORETTI, Franco. More Conjectures. New Left Review, 20 (edição digital), 2003. Disponível em <https://newleftreview.org/ issues/II20/articles/franco-moretti-more-conjectures>. Acesso em 07 jul. 2021.

SAID, Edward. Cultura e Imperialismo. Tradução de Denise Bottman. São Paulo: Companhia das Letras, 2011 (Edição virtual e-book kindle).

SALLES, Ricardo H. A segunda escravidão e o debate sobre a relação entre capitalismo e escravidão. Ensaio de historiografia. In: MUAZE, Mariana; SALLES, Ricardo H (orgs). A segunda escravidão e o império do Brasil em perspectiva histórica. São Leopoldo: Casa Leiria, 2020, pp. 27-52.

SCHWARZ, Roberto. Ao vencedor as batatas: forma literária e processo social nos inícios do romance brasileiro. São Paulo: Ed. 34, 2000.

SLOTERDIJK, Peter. Crítica da razão cínica. Tradução de Marco Casanova, Paulo Soethe, Pedro Costa Rego, Maurício Mendonça Cardozo e Ricardo Hiendlmayer. São Paulo: Estação Liberdade, 2012.

WARWICK RESEARCH COLLECTIVE. Combined and Uneven Development: Towards a New Theory of World Theory. Liverpool: Liverpool University Press, 2015.

Recebido em: 04/08/2021

Aceito em: 16/12/2021 